\section{The Relationship between Family Values and Ethnonationalism in Relation to East Africa (Sub-Saharan)}

\section{Abstract}

Cross-cultural research brings attention to an overarching number of psychological variables such as, amongst others, values, social axioms, cultural tightness/ looseness, cultural orientation and religion, in the report of differences among populations. These psychological variables are often regarded as universal, overlapping nations in different parts of the world. However, recent research observes that as much as human experiences are universal, increased attention needs to be paid to culturally embedded distinctions that emerge from people's description and experiences in their personal context. This study explores the relationship between family values and ethnonationalism in relation to East Africa (sub-Saharan), with specific focus on Tanzania, Kenya and Ethiopia. Examination of the instruments was done through the use of SPSS (version 23). The results indicated that the sub-scales could not be combined to form a total scale score because both ethhnonationalism scale and family values scale had Cronbach's Alpha reliability statistics less than (0.70) and Inter-Item Correlations mean statistics less than (0.20), thus the correlations between the instruments and comparisons between groups needed to be conducted at subscale level. Analysis yielded the following results; there was no correlation between ethnonationalismtheory and family values-hierarchy; there was a weak, positive correlation between ethnonationalism-theory and family-values-relationships; there was no correlation between ethnonationalism-multicultural civic nation and family values-hierarchy; and there was a weak, positive correlation between ethnonationalism-multicultural civic nation and family values-relationships. Recommendations for future research include increasing the number of items in, particularly, the ethnonationalism scale, as neither subscale, one consisting of two items and the other of four items, could be verified as reliable using Cronbach's Alpha reliability statistic. Similarly, one can consider an equal proportion of participants from different groups, thus increasing the likelihood of finding comprehensive differences or further confirming the claim that no significant differences exist within a particular context. Lastly, replicating the use of the same instruments but ensuring a wider age range of participants might promote understand of why, for example, the patterns observed in family values-hierarchy differ so much from the other sub-scales and how this might differ for the elderly compared to the youthful population.

Keywords: Cross-cultural; Psychology; Ethnonationalism; Homogeneity; Multiculturalism

\author{
Janvier Rugira* and \\ Shanel Sampson \\ Department of Psychology, University of \\ Johannesburg, South Africa
}

\section{*Corresponding author: Janvier Rugira \\ jrugira@uj.ac.za}

Lecturer, Faculty of Humanities, Department of Psychology, University of Johannesburg, South Africa.

Tel: 0115593870

Citation: Rugira J, Sampson S (2017) The Relationship between Family Values and Ethnonationalism in Relation to East Africa (Sub-Saharan). Acta Psychopathol Vol. 3 No. 4: 35 .

\section{Introduction}

Since the field of cross-cultural psychology emerged, researchers have questioned whether many of the observations once believed to be universal might apply to cultures outside of the common focus. With extensive cross-cultural literature focussing on variables such as individualism and collectivism, tightness and looseness, or domains such as values presumed to best represent 
important cross-cultural differences; there is a call for increased attention to culturally embedded differences that emerge from cultural groups' personal experiences. It is these experiences within cultural groups that translate into meaningful similarities and differences when bringing different cultures under study. In an attempt to refine variables that truly give enough reliability to distinguish between cultures; this paper is congruent with Saucier et al. [1] in their statement that cross-cultural research would benefit from a consideration of cultural or contextual elements that facilitate well-being or thriving in those communities under consideration. To gain an understanding and perspective on the set of cultural differences that account for more specific and unique attributes of cultures observed, we carefully selected variables that give a description of the countries' culture and heritage.

Broadly, researchers assume that cultural groups give priority to their own goals over the goals of the group they belong to, and define their identity in terms of their personal attributes rather than identifying with the group. In other words, they place greater emphasis on individualism. Conversely, there are those cultural groups that give priority to the goals of their group and define their identity accordingly [2]. The major issue that needs to be addressed, however, is the fact that this one-dimensional approach to studies of cross-cultural psychology is insufficient to support differences that exist or arise in similar oriented societies [3]. For example, conclude that many different kinds of individualism and collectivism exist. For instance, they argue that European individualism is different from American individualism; likewise, the collectivism of Asia may be different from the South African collectivism.

By contrast, results proved support for behaviour and beliefs indicating devotion to religion, ethnonationalism, hierarchal family values, and family oriented collectivism as key locations for crosscultural differences [1]. Saucier et al. [1] recommend that further studies are needed to refine such conclusions. Furthermore, there is a gap evident between population differences in excess of what is typical for psychological variables. Perhaps even a theoretical development of culture is called for, that can best make sense of the profile of ethno-nationalism and traditional hierarchal family values, in how populations differ. In support of such conclusions, this study is directed towards a stronger proportional representation of those countries previously underrepresented in cross-cultural studies, i.e., Tanzania, Ethiopia, and Kenya, and also the importance of common variable selection preferences in cross-cultural psychology.

Anecdotal evidence suggests that Africans have a heritage that help them face more than challenges, and a value system that guides their behaviour at an individual, family and community level, with dominant values that bind communities and ensure social cohesion. These values indeed derive from the old African ages and are grounded in diversity of cultures across its landscapes. For this reason, it is important for nations and communities to look into their own identities and how a country's heritage can help define it.

\section{Statement of the Problem}

Concepts such as individualism and collectivism, social systems, morality and cultural patterns have generated a vast amount of research in respect of cross-cultural psychology since as early as the 1970's [3]. These psychological instruments have formed the basis of selecting and testing individuals from different cultural backgrounds.

However, there are many flaws inherent in this approach. Berry [4] describes this as a tautological trap, in that the very psychological and behavioural data that are used to recognise cultures, are then used to explain psychological and behavioural differences, thus only occupying a marginal status with limited impact in mainstream psychology. These dimensions allow the domain of cultural similarities and differences to be represented broadly and universally, yet a greater need exists for a common variable selection to provide a useful structure for theory and measurement of similarities and differences, especially in multicultural environments like East Africa. These borrowed external elements (universal phenomenon) pose difficulties in transformation and transplanting to suit the characteristics of local regions. By looking into the selected variables, we hope to identify the sources that translate into similarities and differences and make sense of the high profile of ethnonationalism and traditional family values relative to the heritage and identity of countries.

\section{Context of the Study}

East Africa is culturally multi-national and contains numerous ethnic groups. Traditional cultural beliefs and social structures remain strong throughout sub-Saharan Africa. The socialisation of humanity takes place within the context of a larger social unit, often the extended family structure [5]. Unlike contemporary western societies where decisions and practices are carried out collaboratively with much negotiation among parents and children, the transition culture of East Africa, as in many African societies, appears to be more stringent. The larger social unit made up of parents, grandparents, aunts, uncles, siblings, cousins, etc. is much more hierarchal in respect of the importance of people in the group [6]. This, however, does not detract from the more collective approach they take in meeting the group's needs and decisions in rearing the younger generation.

The indigenous social structures in sub-Saharan Africa maintains that women's rights and duties differ from men's, rendering them unequal in the family. Thus, in terms of gender and responsibility, people are considered merely members of their indigenous primary group [7]. Culture is practiced in reverence of cultural values, rather than reverence for life. In other words, what is virtuous and right is what culture values rather than the subjective feelings or opinions of the individual. Howard [8] asserts that the view of human dignity in sub-Saharan Africa is not in accord with the Western concept of individual freedom. Hence the practice observed in this society reflects individuals reverencing what is left of traditional Africa, which is bound up in an individual's fulfilment of her socially approved role: that is, the individual who conforms to society's view of her role as daughter, wife, mother or widow will feel a sense of respect and worthiness. 
Women in sub-Saharan Africa are viewed as the key actors in the process of human development [9]. They exercise their responsibility for the nurturing, rearing, socialisation and education of their children. Because of this responsibility, polygyny is the most distinguishing characteristic of the African family structure [10]. Most of the resources needed are provided by men/fathers, with the resources from woman serving complementary needs. This further discourages woman/girls from expressing ideas and asking questions, resulting in a patriarchal social structure, allowing men to exercise control and woman to be less autonomous.

In addition to these practices related to family values, a characteristic that can once again be taken from earlier times is the dynamics of the elderly. Older woman are commonly dependent in a multi-generational household, most likely headed by older men or boys [11]. This co-residence allows for the transfer or resources that take place between generations.

Another line of thought highlights that the ideology of the quality of life of all members of a society is founded on the assumption that a nation's people are the most important asset for achieving development. Members of East African societies hold in awe and admiration their ancestors and heroes that lived before them, in reverence of their achievements. The relationship between Africans and the land upon which they live derives meaning and sustenance, and shapes their everyday lives. Here people's identities are firmly invested in the homeland, while the homeland, in turn, is steeped in history and powerful cultural and ecological rituals. Sies [12] reminds us that it is impossible to engage properly with a place or person without engaging with all the stories of that place and its people.

The heritage of a cultural group consists of a cumulative record of the influence of humans and the environment in a given context. That is revealed in tangible and intangible evidence that reflects the beliefs and values of that people in that place, at a given time [12]. It can thus be said that individuals' ethnic identity shapes the meaning of the common good. Ethic identity, as applied to Africa, refers to a group sharing common ancestry, language, symbols, and territory [13]. In light of this notion of the common good, East Africa, Kenya specifically because it is multiethnic, now recognises that there is a need to accommodate the substantial diversity, complexity and dynamism in understanding relations between African societies and their environments. This will result in harmonious living between cultural groups.

\section{Methodology}

\section{Participants and setting}

Participants of this study were university students from three countries: Ethiopia, Tanzania, and Kenya. Purposive, nonprobability sampling was utilised. That is, "participants are recruited who share at the heart of the investigation and, if possible, do not vary significantly across demographic characteristics" [14].

From a population size of 8,883 individuals in 33 countries, as presented in the "Study of Worldviews" in 2012, a sample size of 925 individuals was drawn to provide some input data for this specific research project. Tanzania was represented by 256 individuals, 288 from Kenya, and 381 from Ethiopia. Approximately 82 participants were female and 174 male from Tanzania, about 95 females and 193 males in Kenya, and roughly 111 were female and 270 were male in Ethiopia.

To a large extent, the survey and all materials appeared in the major language of the country. The languages used included English (Kenya), in addition the following languages that were country-specific: Kiswahili (Tanzania), and Amharic (Ethiopia).

\section{Measuring instruments}

The survey used items drawn from measures of nearly 50 variables drawn from 17 distinct sources, each involving, in some way, shared beliefs, values, and norms that might be shared across persons [1]. For the purpose of this study we consider the following two sources to guide the selection of variables.

Family values scales: This eight item scale measures two dimensions, namely hierarchy (i.e., focused on gender roles) and relationships (i.e., cohesiveness, reputation, obligations). Respondents indicate to what extent they agree or disagree with a set of statements. On the one hand the scale measures person's beliefs about the father's place in the house, mother's place in the house, father's responsibility in the family, and mother's role towards her spouse. On the other hand, the scale measures children's attitude towards elders, children's obligations to grandparents, family cohesiveness and attitude towards family's reputation. Respondents indicate their beliefs or views of significant others in their lives on a continuum ranging from "1-strongly disagree", "2-moderately disagree", "3-slightly disagree", "4-slightly agree", "5-moderately agree", or "6-strongly agree". Respondents who strongly agree that the father should be the head of the house, for example, report on strongly agree. Likewise, those who place emphasis on the submissive role of women and children in the household are likely to score very high-"strongly agree"-relative to that item. To be categorised as placing great emphasis on the importance of others in their lives, respondents are likely to "moderately" or "strongly" agree with the given items. Alternatively, should they place less emphasis on the cohesiveness of the family or place greater emphasis on roles being played interchangeably between mothers and fathers, and children reared to live independently, respondents are likely to "moderately" or "strongly" disagree with the given items. Participants who do not always fit the extreme beliefs or views either "slightly" agree or disagree to the given statements.

Ethno-nationalism: This instrument compromises four items capturing ethnonationalism as in the theory of Anthony D. Smith, and two items capturing a multiculturalist civic nationalism [1]. Respondents indicate to what extent they agree or disagree to a set of statements. On the one hand, the scale measures various views about personal philosophy, human nature, opinions, and beliefs about their homeland, ancestors, heritage, and heroes. On the other hand, the scale measures person's views and acceptance about diversity and multiculturalism. Respondents indicate their beliefs or philosophies on a continuum ranging from "1-strongly disagree", "2-moderately disagree", "3-slightly disagree", "4-slightly agree", "5-moderately agree", or "6-strongly agree". Respondents, who regard their homeland as sacred, carry 
loyalty for their heritage, language, and religion, for example, report on "strongly agree". Likewise, those who place great emphasis on diversity and ethnic plurality are likely to score very high-"strongly agree"-relative to that item. To be categorised as having a common ideology, common institutions and customs, and a sense of homogeneity, or shared heritage which usually includes a common language, a common faith, and a common ethnic ancestry, respondents are likely to "moderately" or "strongly" agree with the given items. Alternatively, should they place less emphasis on the ideas of a culture shared between members of the group, and with their ancestors, respondents are likely to "moderately" or "strongly" disagree with the given items. Participants who do not always fit the extreme beliefs or views either "slightly" agree or disagree to the given statements.

\section{Data Analysis}

We first looked at frequencies and simple descriptive statistics (viz. age, gender, marital status, parental status, and computer use), computed for demographic variables and the dependent measures. This provided a quantitative picture of data collected from the participants in each demographic area. The dependent variable included in the analysis is "family values", and the independent variable included in the analysis is "ethnonationalism". Next, we tested for reliabilities to test the stability or consistency of the measure [15] for multicultural relevance of each sub-scale. The third analysis performed was normality of the distribution to determine whether we could use parametric or non-parametric tests. The test used to test for this normality is the Kolmogorov-smirnov test which is validated because we have a sample size of 925 individuals, a sample size exceeding 50, not only for the entire sample but also each of the three groups representing the sample.

The fourth analysis performed was to determine whether there were significant correlations between family values and ethnonationalism. Because our two scales are made up of two sub-scales each, we thus performed a correlation analysis for family values (hierarchy) and ethnonationalism (theory); family values (hierarchy) and ethnonationalism (multiculturalism); family values (relationship) and ethnonationalism (theory); and family values (relationship) and ethnonationalism (multiculturalism). Again, depending on the normality of the scores, we determined the significant correlations using Pearson's correlation for normally distributed (parametric tests) and Spearman's rank for distribution that were not normally distributed (non-parametric tests).

The last analysis performed was normality and comparisons between and within the three groups of interest (Tanzania, Kenya, and Ethiopia). When testing the distribution per group, we will consider the normality for each group, again using the Kolmogorov-smirnov test which is validated, as earlier stated, because even the individual groups had sample sizes exceeding 50 , that is 256,288 , and 381 for Tanzania, Kenya, and Ethiopia respectively. The following tests, One-Way ANOVA or Robust Test of Equality of Means, were used when testing the differences between our three independent groups based on the variances. Because equal (homogeneity) variances are assumed, One-
Way ANOVA test was used. Should there be no equal variances amongst respondents the Robust Test of Equality of Means table would be used.

To go a step further, we determined where the differences lay exactly between the three groups using the Post Hoc Tests. Posthoc Scheffe's tests was used for multiple comparisons between the three groups, in those instances where equal (homogeneity) variances are assumed as compared to the Dunnett's T3 test when equal variances are not assumed.

\section{Results}

\section{Frequencies and descriptive}

Frequency and descriptive statistics are presented below to describe the characteristics of the sample. These descriptive statistics include the number of participants for each group/ country in the sample, the mean age of the sample, gender distribution of the sample, marital status and parental status distribution of the sample, and means report on the family values scale and ethnonationalism scale on item level.

The sample is representative of 925 individuals; Ethiopia had the largest sample pull of 381 participants representing $41 \%$ of responses in the study, this is followed by 288 participants from Kenya representing $31 \%$ of responses in the study, and then 256 participants from Tanzania representing $28 \%$ of the responses in the study. The mean age indicates quite a young sample, with a statistical mean value of 24.46 and standard deviation of 4.726 . This means that between 20 and 30 is where most people's ages lie. Gender descriptives indicate that $68 \%$ of participants were male and $32 \%$ were female (Table 1 ).

The sample being drawn from college students there is no surprise that marital status yielded the following results: $86 \%$ were single and never married, $14 \%$ married, and 3 widowed, separated, or divorced. Notably, $16 \%$ said yes, they were parents, yet $84 \%$ had no dependents. The assumption now can be that we expect less agreement to the items on the family value scales with regards to gender roles and individuals' perception on relationships in the family because the majority of the sample is single, and never married, and most never experienced the dynamic of parenting (Table 2).

Table 1 Geographical, age and gender distribution of participants.

\begin{tabular}{|c|c|c|c|c|c|}
\hline \multirow{2}{*}{ Country } & \multicolumn{2}{c}{ Population } & Mean Age & \multicolumn{2}{c|}{ Gender } \\
\hline Tanzania & 256 & 27.7 & 24.8 & 174 & 82 \\
\hline Kenya & 288 & 31.1 & 24.6 & 193 & 95 \\
\hline Ethiopia & 381 & 41.2 & 24 & 270 & 111 \\
\hline Total & 925 & 100 & - & 637 & 288 \\
\hline
\end{tabular}

Table 2 Marital status and parental status distribution of participants.

\begin{tabular}{|c|c|c|c|}
\hline \multirow{2}{*}{ Marital status } & Frequency & Percent \\
\cline { 2 - 4 } & Single and never married & 678 & 85.9 \\
\cline { 2 - 4 } & $\begin{array}{c}\text { Married } \\
\text { Widowed, separated, or } \\
\text { divorced }\end{array}$ & 108 & 13.7 \\
\hline Parental & Yes & 122 & 0.4 \\
\hline status & No & 664 & 84.5 \\
\hline
\end{tabular}


The two measurement scales, family values and ethnonationalism, reported to a six point Likert-scale from "strongly disagree" to "strongly agree" highlighted the following patterns in relation to participants preferences for the set of questions: participants overall slightly and moderately agree to the set of items on ethnonationalism, however while they may moderately agree to the set of items based on obligation, cohesiveness, family reputation and relationship with grandparents, they moderately and even slightly disagree with the items addressing gender roles. Generally, participants tended more to the moderately agree side of the family values-relationship scale, and more to the slightly agree side to both ethnonationalism scales, compared to tending more towards the slightly disagreeing side of the family valuesgender roles scale (Tables 3 and 4).

\section{Reliability testing for family values and ethnonationalism}

When selecting scales to include in the study it is important to ensure that the scales are reliable. Sometimes scales like the ethnonationalism and family values contain a number of subscales that may or may not be combined to form a total scale score. Thus, it is necessary that the reliability of each of the subscales and total scales be calculated. Cronbach's Alpha values equal to or above 0.70 are considered acceptable, reliable. With short scales (e.g., scales less than 10 items) it is common to find quite low Cronbach's Alpha values (e.g., 0.50). In this case an alternative statistic, Inter-Item Correlations means, is also reported. Inter-Item Correlations mean values between 0.20 and 0.40 are considered acceptable, reliable (Table 5).

Table 3 Means: report-ethnonationalism scale.

\begin{tabular}{|c|c|c|}
\hline & Mean & Standard Deviation \\
\hline EN1 & 3.47 & 1.72 \\
\hline EN2 & 4.92 & 1.29 \\
\hline EN3 & 4.95 & 1.22 \\
\hline EN4 & 4.38 & 1.4 \\
\hline EN5 & 4.92 & 1.25 \\
\hline EN6 & 3.65 & 1.7 \\
\hline
\end{tabular}

Note: Ethnonationalism-theory had a mean of 4.11 and a standard deviation of 1.02; Ethnonationalism-multicultural civic nation had a mean of 4.20 and a standard deviation of 1.04

Table 4 Means: report-family values scale.

\begin{tabular}{|l|c|c|}
\hline & Mean & Standard Deviation \\
\hline FV1 & 4.31 & 1.64 \\
\hline FV2 & 5.17 & 1.17 \\
\hline FV3 & 2.64 & 1.73 \\
\hline FV4 & 5.04 & 1.2 \\
\hline FV5 & 3.15 & 1.63 \\
\hline FV6 & 5.11 & 1.17 \\
\hline FV7 & 3.57 & 1.49 \\
\hline FV8 & 5.27 & 1.08 \\
\hline
\end{tabular}

Note: Family values-hierarchy had a mean of 3.42 and a standard deviation of 1.19; Family values-relationships had a mean of 5.14 and a standard deviation of 0.89

\section{Level of significance}

The level of significance in this study was set at 0.05 using a twotailed probability.

\section{Normality testing and correlation between family values and ethnonationalism}

The Kolmogorov-Smirnov test substantiated that none of the four sub-scales had p-values equal to or exceeding 0.05 thus the tests are not normally distributed.

Although the Kolmogorov-Smirnov test proves that the variables are not normally distributed, correlations were analysed and reported using a parametric correlations test supported by the large sample size of 925 individuals, which makes the test quite robust. The relationship between ethnonationalism-theory and family values-hierarchy, ethnonationalism-theory and family values-relationships, ethnonationalism-multicultural civic nation and family values-hierarchy, and ethnonationalism-multicultural civic nation and family values-relationships was investigated using Pearson correlation coefficient (Table 6).

Correlation analysis is used to describe the strength and direction of the linear relationship between two variables. Any $p$-value (sig 2-tailed) $<0.05$ shows a statistically significant correlation and Pearson correlation is an indication of how strong the correlation is. This can range from -1.00 to 1.00. A correlation of 0 indicates no relationship at all, a correlation of +1 indicates a perfectly positive correlation, and a correlation of -1.00 indicates a perfectly negative correlation.

Table 7 provides the following results: There was no correlation between ethnonationalism-theory and family values-hierarchy; there was a weak, positive correlation between ethnonationalismtheory and family-values-relationships, $p=0.00$ and $r=0.15$; there was no correlation between ethnonationalism-multicultural civic

Table 5 Reliability: report-Cronbach's alpha and inter-item correlations mean for each subscale.

\begin{tabular}{|c|c|c|}
\hline Sub-Scales & $\begin{array}{c}\text { Cronbach's } \\
\text { Alpha }\end{array}$ & $\begin{array}{c}\text { Inter-Item } \\
\text { Correlations Mean }\end{array}$ \\
\hline Ethnonationalism-theory & 0.58 & 0.25 \\
\hline $\begin{array}{c}\text { Ethnonationalism- } \\
\text { multiculturalist civic nation }\end{array}$ & 0.47 & 0.31 \\
\hline Family values-hierarchy & 0.7 & 0.38 \\
\hline Family values-relationships & 0.77 & 0.45 \\
\hline
\end{tabular}

Note 1: Ethnonationalism scale as a whole had a Cronbach Alpha reliability statistic of 0.59 and an Inter-Item Correlations mean statistic of 0.19

Note 2: Family values scale as a whole had a Cronbach Alpha reliability statistic of 0.57 and an Inter-Item Correlations mean statistic of 0.15

Table 6 Kolmogorov-Smirnov test.

\begin{tabular}{|c|c|c|c|}
\hline & Statistic & Df & Sig. \\
\hline EN theory & 0.085 & 893 & 0 \\
\hline EN Multicultural civic nation & 0.165 & 892 & 0 \\
\hline FV hierarchy & 0.057 & 891 & 0 \\
\hline FV relationships & 0.173 & 891 & 0 \\
\hline
\end{tabular}


Table 7 P-value and Pearson's correlations for the four sub-scales.

\begin{tabular}{|c|c|c|c|c|c|}
\hline Correlations & & EN Theory & EN Multicultural & FV Hierarchy & FV Relationships \\
\hline \multirow{3}{*}{ EN theory } & Pearson Correlation & 1 & $0.205^{* *}$ & 0.035 & $0.153^{* *}$ \\
\hline & Sig. (2-tailed) & - & 0 & 0.299 & 0 \\
\hline & $\mathrm{N}$ & 893 & 892 & 870 & 870 \\
\hline \multirow{3}{*}{ EN multicultural civic nation } & Pearson Correlation & $0.205^{* *}$ & 1 & -0.031 & $0.370^{* *}$ \\
\hline & Sig. (2-tailed) & 0 & - & 0.364 & 0 \\
\hline & $\mathrm{N}$ & 892 & 892 & 869 & 869 \\
\hline \multirow{3}{*}{ FV hierarchy } & Pearson Correlation & 0.035 & -0.031 & 1 & $-0.099^{* *}$ \\
\hline & Sig. (2-tailed) & 0.299 & 0.364 & - & 0.003 \\
\hline & $\mathrm{N}$ & 870 & 869 & 891 & 891 \\
\hline \multirow{3}{*}{ FV relationships } & Pearson Correlation & $0.153^{* *}$ & $0.370^{* *}$ & $-0.099^{* *}$ & 1 \\
\hline & Sig. (2-tailed) & 0 & 0 & 0.003 & - \\
\hline & $\mathrm{N}$ & 870 & 869 & 891 & 891 \\
\hline
\end{tabular}

nation and family values-hierarchy; there was a weak, positive correlation between ethnonationalism-multicultural civic nation and family values-relationships, $p=0.00$ and $r=0.37$. Although the correlation between ethnonationalism-multicultural civic nation and family values-relationships was also weak, it was stronger than that of ethnonationalism-theory and family-valuesrelationships.

\section{Normality and comparisons between Tanzania, Kenya, and Ethiopia}

The Kolmogorov-Smirnov test was used to test for normality. The test produced non-normality for each of the three countries under the four sub-scales with $p$-values $<0.05$. Thus each group separately on their scores is not normally distributed (Table 8).

Comparisons between the groups were done using a parametric test. In spite of the normality test resulting in no normality for each of the three countries relative to the sub-scales, it is quite robust. For this reason, the One-Way ANOVA was used. Results from the One-Way ANOVA table illustrated mean values and standard deviation values for the three countries as illustrated in Table 9.

In order to compare the observed scores represented above between groups we tested for variances. In this case a $p$-value $\geq 0.05$ describes equal variances. Results show that for Ethnonationalism-theory with a $p$-value $=0.10$ and family values-hierarchy with a $p$-value of 0.20 the variances were equal between the three groups, alternatively for ethnonationalismmulticultural civic nation with a $p$-value of 0.00 and family valuesrelationship with a $p$-value $=0.00$ the variances were not equal between the three groups.

Below we look at the ANOVA table where variances between the three groups were equal and the Robust test for equality of means where variances between the three groups were not equal (Tables 10 and 11).

A $p$-value $\leq 0.05$ demonstrates differences between the three groups on how they responded to items on the scales. The ANOVA table where variances between the three groups were
Table 8 Test for normality: Kolmogorov-Smirnov-for Tanzania, Kenya, and Ethiopia.

\begin{tabular}{|c|c|c|c|c|}
\hline Country & & Statistic & df & Sig. \\
\hline \multirow{3}{*}{ EN theory } & Tanzania & 0.083 & 244 & 0 \\
\hline & Kenya & 0.099 & 278 & 0 \\
\hline & Ethiopia & 0.088 & 371 & 0 \\
\hline \multirow{3}{*}{ EN multiculturalism } & Tanzania & 0.155 & 244 & 0 \\
\hline & Kenya & 0.206 & 278 & 0 \\
\hline & Ethiopia & 0.162 & 370 & 0 \\
\hline \multirow{3}{*}{ FV hierarchy } & Tanzania & 0.066 & 238 & 0.014 \\
\hline & Kenya & 0.076 & 279 & 0.001 \\
\hline & Ethiopia & 0.085 & 374 & 0 \\
\hline \multirow{3}{*}{ FV relationships } & Tanzania & 0.178 & 238 & 0 \\
\hline & Kenya & 0.229 & 279 & 0 \\
\hline & Ethiopia & 0.154 & 374 & 0 \\
\hline
\end{tabular}

Table 9 Mean: report-for Tanzania, Kenya, and Ethiopia in relation to sub-scales.

\begin{tabular}{|c|c|c|c|c|}
\hline One-way ANOVA & & N & Mean & Std. Deviation \\
\hline \multirow{3}{*}{ EN theory } & Tanzania & 244 & 3.78 & 1.009 \\
\hline \multirow{5}{*}{ EN multiculturalism } & Kenya & 278 & 4.12 & 1.047 \\
\cline { 2 - 5 } & Ethiopia & 371 & 4.32 & 0.947 \\
\hline & Total & 893 & 4.11 & 1.019 \\
\hline & Tanzania & 244 & 4.9 & 0.978 \\
\hline \multirow{5}{*}{ FV hierarchy } & Kenya & 278 & 5.21 & 0.907 \\
\hline & Ethiopia & 370 & 4.7 & 1.108 \\
\hline & Total & 892 & 4.92 & 1.035 \\
\hline \multirow{5}{*}{ FV relationships } & Tanzania & 238 & 3.72 & 1.167 \\
\cline { 2 - 5 } & Kenya & 279 & 3.66 & 1.088 \\
\hline & Ethiopia & 374 & 3.05 & 1.176 \\
\hline & Total & 891 & 3.42 & 1.188 \\
\hline & Kanzania & 238 & 5.21 & 0.784 \\
\hline & Kenya & 279 & 5.35 & 0.829 \\
\hline & Ethiopia & 374 & 4.94 & 0.954 \\
\hline
\end{tabular}

equal ethnonationalism-theory and family values-hierarchy both had a $p<0.05$ implying there is a difference between the three groups. Likewise the Robust test for equality of means 
Table 10 Homogeneity of variances between sub-scales.

\begin{tabular}{|c|c|c|c|c|}
\hline & Levene's Statistic & df1 & df2 & Sig. \\
\hline EN theory & 2.348 & 2 & 890 & 0.096 \\
\hline EN multiculturalism & 10.13 & 2 & 889 & 0 \\
\hline FV hierarchy & 1.616 & 2 & 888 & 0.199 \\
\hline FV relationships & 7.119 & 2 & 888 & 0.001 \\
\hline
\end{tabular}

Table 11 ANOVA: report-variances for ethnonationalism-theory and family values-hierarchy.

\begin{tabular}{|c|c|c|}
\hline & & Sig. \\
\hline EN theory & Between Groups & 0.000 \\
\hline FV hierarchy & Between Groups & 0.000 \\
\hline
\end{tabular}

table where variances between the three groups are not equal, ethnonationalism-multicultural civic nation and family valuesrelationships both had a $p<0.05$ implying there is a difference between the three groups.

In going a step further to see where the differences lies (between which groups) as differences were substantiated by the ANOVA table and Robust test for the equality of means, Post-Hoc tests were employed. Again p-value $\leq 0.05$ demonstrates differences between two groups under testing. The Scheffe Post-Hoc test was employed where variances were equal and the Dunnett T3 test for where variances were not equal. The Scheffe Post-Hoc test showed significant differences between all three countries with a $p$-values $<0.05$. Whereas the Dunnett T3 test showed significant differences between Tanzania and Kenya with a p-value $=0.01$, and between Kenya and Ethiopia with a $p$-value $=0.00$, however no significant differences between Tanzania and Ethiopia with a p-value $=0.06$ (Tables 12-14).

\section{Discussion}

The ultimate goal of this study was to examine the relationship between ethnonationalism and family values, to ascertain whether a statistically significant relationship exists between these two constructs. More specifically, an additional goal was to observe the patterns of the two variables within and between the three countries under study (Tanzania, Kenya, and Ethiopia). In doing so we wanted to determine whether any variances exist in the variables between the three nations, and if so, among which nations these variances lie.

\section{Frequencies and descriptive}

Hypothesis 1: People in East Africa generally hold ancient beliefs and loyalties to their homelands, heritage, and ancestors or heroes: Results show that participants "slightly" to "moderately agree" that their homeland is sacred because of its monuments and to their ancestors and heroes, that they honour the people who have sacrificed themselves for their destiny and heritage, that the glorious ages were marked by glorious beautiful achievements, and that their loyalty lies with their heritage, language, and religion.

This thus confirms our hypothesis that people in East Africa generally hold ancient beliefs and loyalties to their homeland, heritage, and ancestors and heroes. Literature by Milbourne and
Hill, confirms that the relationship between Africans and their land helps them derive meaning and serves as their provision; it contours their lives. East African societies like many African societies are drenched in history and influential cultural and ecological sacraments.

Hypothesis 2: East Africa it is a nation built of many different cultures and its people are generally welcoming to diversity: Results show that participants "moderately agreed" that they value being a citizen of a nation that is diverse, i.e., with more than one religion, language and ethnicity, and they are very open to many different cultures.

Thus, it confirms our hypothesis that East Africa is a multicultural civic nation and that its people are welcoming of diversity. Many theorists like Conner [13] maintain that East Africa is culturally multi-national and contains numerous ethnical groups. Tarimo [16] sustains this claim by saying East African countries, Kenya specifically, is a multi-ethnic society, and many of its communities have lived in harmony for many years. She however brings to our attention the fact that in recent years the dominant ethnic group has been on the forefront fighting for political power, presenting the pattern and consequences of ethno-political competition, discrimination, and violence. If this is a perverse form of regionalism, then this forced movement will result in ideologies other than those that hold modern democracies together [16]. With this knowledge it would be interesting to see how participants respond to multiculturalism civic nation items in the future should the regionalism forcing succeed.

Table 12 Robust test for equality of means: report-variances for ethnonationalism-multicultural civic nation and family valuesrelationships.

\begin{tabular}{|l|l|c|}
\hline & & Sig. \\
\hline EN multicultural & Brown-Forsythe & 0.000 \\
\hline FV relationships & Brown-Forsythe & 0.000 \\
\hline
\end{tabular}

Table 13 Scheffe post-hoc test: equal variances.

\begin{tabular}{|c|c|c|c|c|}
\hline Country & & Mean Difference & $\begin{array}{c}\text { Std. } \\
\text { error }\end{array}$ & Sig. \\
\hline Tanzania & Kenya & $-0.339^{*}$ & 0.087 & 0.001 \\
\hline & Ethiopia & $-0.541^{*}$ & 0.082 & 0 \\
\hline \multirow{2}{*}{ Kenya } & Tanzania & $0.339^{*}$ & 0.087 & 0.001 \\
\hline & Ethiopia & $-0.202^{*}$ & 0.079 & 0.038 \\
\hline Ethiopia & Tanzania & $0.541^{*}$ & 0.082 & 0 \\
\hline & Kenya & $0.202^{*}$ & 0.079 & 0.038 \\
\hline
\end{tabular}

Table 14 Dunnett T3 test: variances are not equal.

\begin{tabular}{|c|c|c|c|c|}
\hline \multirow{2}{*}{ Country } & & Mean Difference & Std. error & Sig. \\
\hline \multirow{2}{*}{ Kanzania } & Kenya & $-0.312^{*}$ & 0.083 & 0.001 \\
\cline { 2 - 5 } & Ethiopia & 0.198 & 0.085 & 0.061 \\
\hline \multirow{2}{*}{ Ethiopia } & Tanzania & $0.312^{*}$ & 0.083 & 0.001 \\
\cline { 2 - 5 } & Ethiopia & $0.510^{*}$ & 0.079 & 0 \\
\hline & Tanzania & -0.198 & 0.085 & 0.061 \\
\hline & Kenya & $-0.510^{*}$ & 0.079 & 0 \\
\hline
\end{tabular}




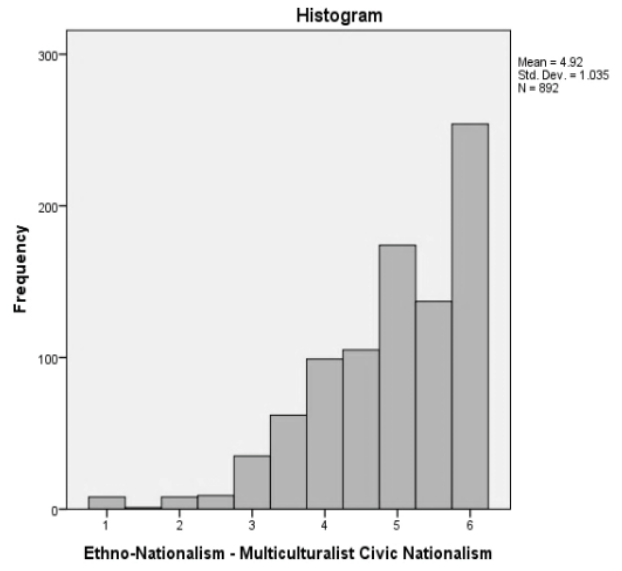

Not normally distributed: negatively skewed

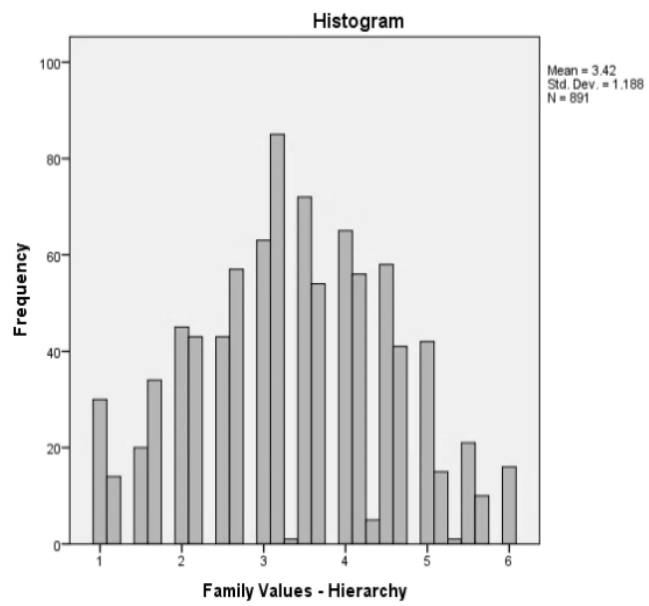

Not normally distributed: positively skewed

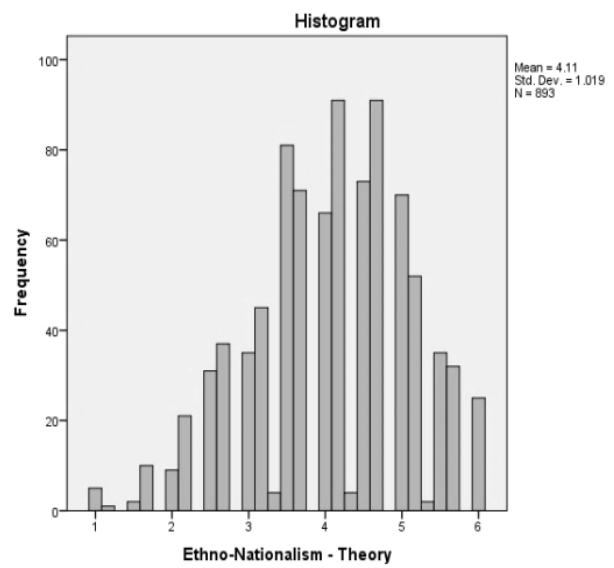

Not normally distributed: negatively skewed

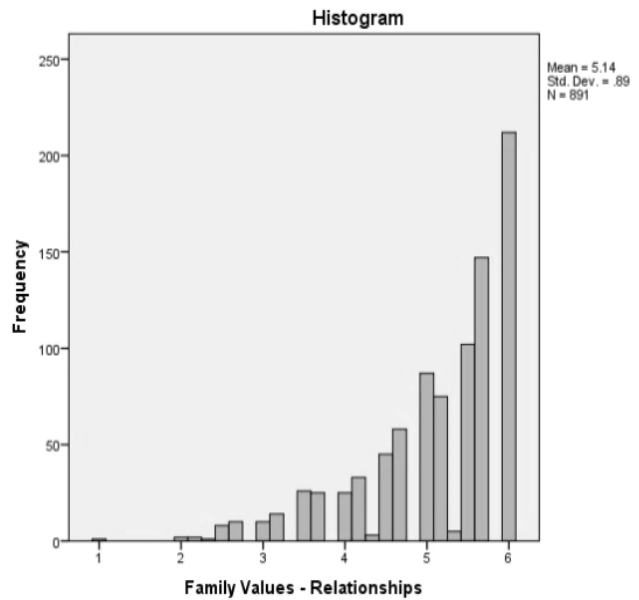

Not normally distributed: negatively skewed

Figure 1 Test of normality: histograms for four sub-scales.

Hypothesis 3: In East Africa people generally follow a hierarchal value system: Of all scales, family values-hierarchy probably yielded the most interesting results. Results show that participants "moderately agreed" that the father should be the head of the house and that the mother should accept the decision of the father, however they "slightly disagree" that the mother's place is in the home and that the mother should accept the decisions of the father.

Researchers like Browne and Hazel [9], and Walter et al. [10] assert that women in many societies, as in East African, exercise their influence in socialising, fostering, and nurturing their children. Women are disheartened for expressing their ideas and asking questions, allowing men to exercise control and woman to be less autonomous. Although literature confirms our hypothesis, the results of the study do not. We may conclude that this is due to a shift in thinking, beliefs and philosophy of the participants. It is important to note that the majority of the participants were between 20 and 30 years old, thus their beliefs are less stringent than the elderly in society, which literature reflects, and in which such beliefs persist.

Hypothesis 4: In East Africa people generally value relationships, obligations, and the family's reputation: Results for family values-relationships show that participants generally "moderately agree" to support the elderly when they age, exhibit a sense of cohesiveness within the family, an honour for the elderly, as well as the family's reputation.

The hypothesis is in relation to the results obtained. The family usually takes the form of an extended family made up of parents, grandparents, siblings, aunts, uncles, cousins, etc. Although certain roles are clearly outlined in the family, the family does make a collective effort concerning their survival and development [6]. They further confirm that since earlier days the characteristic that perpetuates is the dynamics of the elderly, most likely regulated by older children, whilst there is a transfer of resources between younger and older generations. 


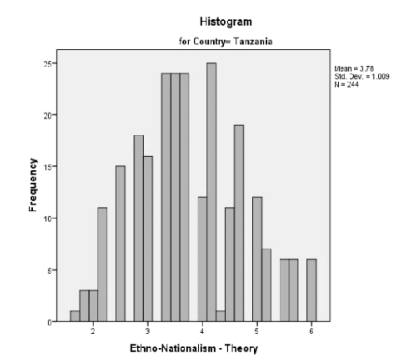

Not normally distributed: positively skewed

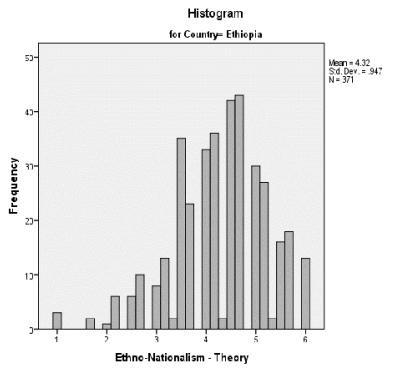

Not normally distributed: negatively skewed

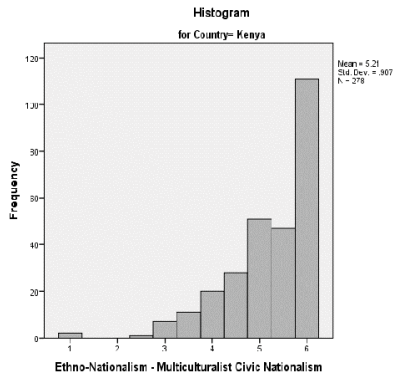

Not normally distributed: negatively skewed

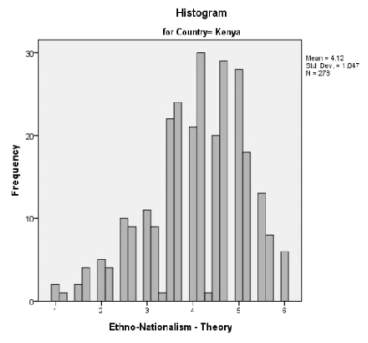

Not normally distributed: negatively skewed

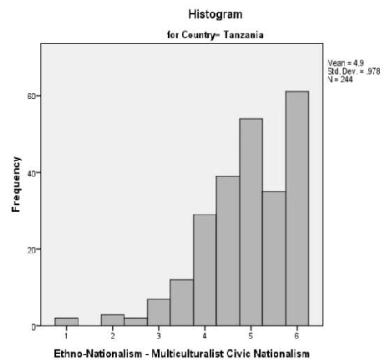

Not normally distributed: negatively skewed

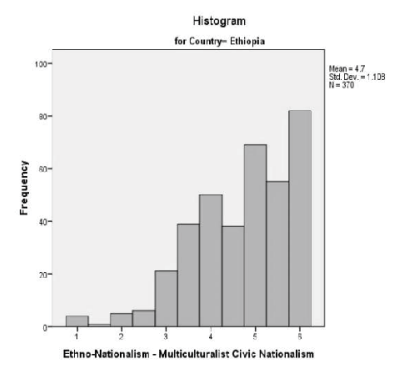

Not normally distributed: negatively skewed

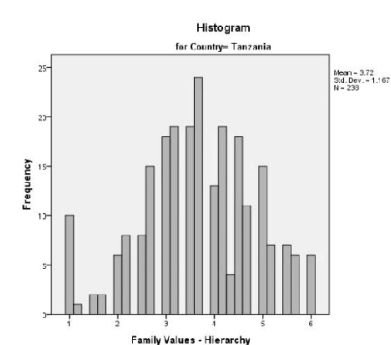

Not normally distributed: negatively skewed

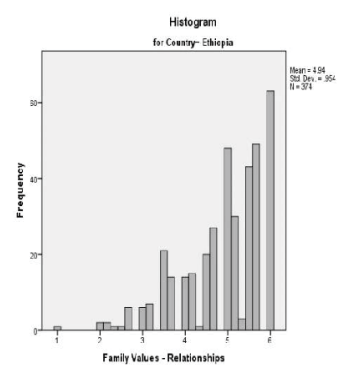

Not normally distributed: negatively skewed

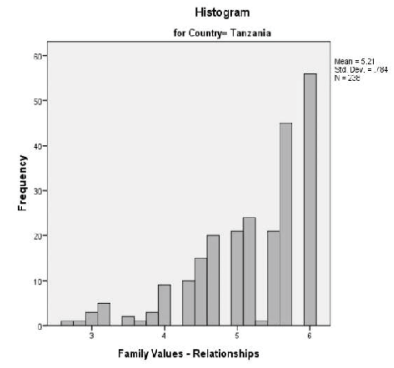

Not normally distributed: negatively skewed

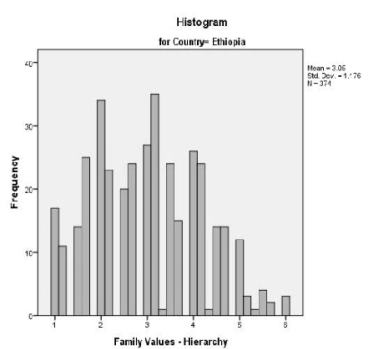

Not normally distributed: positively skewed

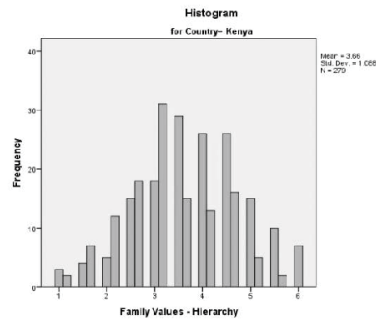

Not normally distributed: negatively skewed

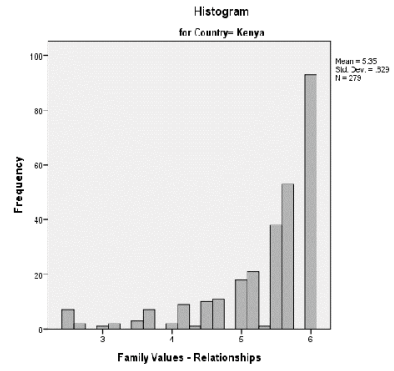

Not normally distributed: negatively skewed

Figure 2 Test of normality: histograms for four sub-scales in relation to Tanzania, Kenya, and Ethiopia.

\section{Reliability testing, normality testing and correlation between family values and ethnonationalism}

Hypothesis 5: There is a correlation between family values and ethnonationalism: As noted earlier, when selecting scales to be included in the study and, even more so, to correlate, we have to ensure the reliability of the scales. That is to certify that the scale measures what is intended to be measured. Because both the ethhnonationalism scale and family values scale had Cronbach's Alpha reliability statistics less than 0.70 and InterItem Correlations mean statistics less than 0.20 , the sub-scales could not be combined to form a total scale score. For this reason, the reliability of each of the sub-scales had to be calculated. Family values-hierarchy scale had a Cronbach's Alpha reliability statistic of (0.70) and the family values-relationship scale a Cronbach's Alpha of (0.77). This is to say the items in the scale successfully and reliably measure family values-relationships and family values-hierarchy. In addition to this we reported the Inter-Item correlations mean for ethnonationalism-theory with a reliability statistic of (0.25) and the Inter-Item correlations mean for ethnonationalism-multicultural civic nation with a reliability statistic of (0.31). One reason for the ethnonationalism scale and sub-scales not showing reliability is the number of items in the scale.
It is interesting to note that the ethnonationalism-multicultural civic nation scale that only has two items has a higher Inter-Item correlationa mean value (0.31) than the ethnonationalism-theory (0.25) that has four items. One implication may be that the items included in ethnonationalism theory need to be revised and some disregarded and replaced.

The Kolmogorov-Smirnov test substantiated that the tests are not normally distributed as none of the four sub-scales had $p$-values $\geq 0.05$. The histograms used to display the distributions for ethnonationlism-theory, ethnonationalism-multicultural civic nation, family values-hierarchy, and family values-relationships are presented below.

The Figure 1 show that ethnonationalism-multicultural civic nation, ethnonationalism-theory, and family values-relationships are all negatively skewed, meaning most responses are found on the "agreeable" end of the scale. On the other hand, family values-hierarchy is positively skewed meaning most responses are found on the "disagreeable" end of the scale.

Overall the Kolomogorov-Smirnov test provide the following p-values and Pearson's correlations results; there was no correlation between ethnonationalism-theory and family values- 
hierarchy; there was a weak, positive correlation between ethnonationalism-theory and family-values-relationships, $p=0.00$ and $r=0.15$; there was no correlation between ethnonationalismmulticultural civic nation and family values-hierarchy; there was a weak, positive correlation between ethnonationalismmulticultural civic nation and family values-relationships, $p=0.00$ and $r=0.37$. Although the correlation between ethnonationalismmulticultural civic nation and family values-relationships is also weak, it is stronger than that of ethnonationalism-theory and family-values-relationships.

The positive correlation between ethnonationalism-theory and family-values-relationships implies the more people agree on theory, the more they agree on relationships. In other words, people's views about significant others in their immediate lives also influence their views and philosophies about their heritage, culture, ancestors, and heroes. Also, the positive correlation between ethnonationalism-multicultura, civic nation and family-values-relationships implies the more people agree on multiculturalism, the more they agree on relationships. In other words, people's acceptance and relationship with significant others in their lives influences their openness to other cultures, including diversity.

\section{Normality and comparisons between Tanzania, Kenya, and Ethiopia}

Hypothesis 6: There are differences in family values (Hierarchal), family values (Relationships), ethnonationalism (Theory), and ethnonationalism (Multicultural civic nation) for people in Tanzania, Ethiopia, and Kenya: The Kolmogorov-Smirnov test was used to test for normality. The test substantiated nonnormality for each of the three countries under the four subscales with $p$-values $<0.05$. Thus each group separately on their scores is not normally distributed. The histograms used to display the distributions for ethnonationlism-theory, ethnonationalismmulticultural civic nation, family values-hierarchy, and family values-relationships as they interact in each of the three nations in the study are presented below.

The Figure $\mathbf{2}$ show that ethnonationalism-theory is negatively skewed in Ethiopia and Kenya, meaning most responses are found on the "agreeable" end of the scale, but positively skewed in Tanzania meaning most responses are found on the "disagreeable" end of the scale. Ethnonationalism-multicultural civic nation is negatively skewed in Tanzania, Ethiopia and Kenya, meaning most responses are found on the "agreeable" end of the scale. Family values-hierarchy is negatively skewed in Tanzania and Kenya, meaning most responses are found on the "agreeable" end of the scale, but positively skewed in Ethiopia meaning most responses are found on the "disagreeable" end of the scale. Lastly, family values-relationship is negatively skewed in Tanzania, Ethiopia and Kenya, meaning most responses are found on the "agreeable" end of the scale

Subsequently, results show that for Ethnonationalism-theory and family values-hierarchy with the variances were equal between the three groups, alternatively for ethnonationalism-multicultural civic nation and family values-relationship the variances were not equal between the three groups. Finally, to see where the difference lies (between which groups) the Scheffe Post-Hoc test showed significant differences between all three countries, whereas the Dunnett T3 test showed significant differences between Tanzania and Kenya, and between Kenya and Ethiopia, however, no significant differences between Tanzania and Ethiopia.

Based on the above information, in relation to the means, Ethiopia is the highest on ethnonationalism-theory, followed by Kenya, and Tanzania the lowest. Ethnonationalism-multiculturalism displays Ethiopia and Tanzania are on the same level lower on multiculturalism, and Kenya is higher on multiculturalism. In addition to this family value hierarchy displayed, Tanzania and Kenya are higher on hierarchy, both differing from Ethiopia which is lower on hierarchy and lastly family values-relationships Tanzania and Kenya are higher on relationships than Tanzania. Thus, it can be said, Tanzania and Kenya are higher on the scale of family relations compared to Ethiopia.

\section{Limitations and Future Directions}

The current study is susceptible to a number of limitations that need to be kept in mind. Firstly, the study wanted a comprehensive representative of the Global South to see whether there are significant differences between countries Tanzania, Kenya, and Ethiopia, however the sample was largely made up of participants from Ethiopia (41\%), followed by Kenya (31\%), and then Tanzania (28\%). This unequal distribution thus has a biased impact on the total scale score, if we were to use this to report on differences between the three nations. Future research should aim at obtaining an equivalent number of participants from each geographical area, should comparisons want to be made across different nations.

Another limitation from the sample is that demographical variables for age presented a mean age of 25 and standard deviation of 5 . This implies that the majority of ages were in the range between 20 and 30 . This too provides a biased view of participants' responses as a younger population's responses, preferences, views, and beliefs are most likely to be different from the elderly in the population. Future research should attempt to get an equally distributed sample of ages when comparing philosophies, views, or beliefs, as these are likely to change for people depending on the developmental age.

Lastly, the ethnonationalism-theory and ethnonationalismmulticultural civic nation sub-scales proved to not be reliable. This is because they both lack the minimum required number of items for the scale to consistently measure what it intends to measure. Items in these scales need to be revised, and sufficient items need to be added to increase reliability.

\section{Conclusion}

Analysis and results confirm that the majority of participants in our sample represent Tanzania which makes up $41.2 \%$ of our general sample, that the mean age of the sample is 24.46 with the most popular ages lying between 20 and 30 years of age, and also that a larger portion of the sample were male, representing $68 \%$ of participants. In addition to this, $86 \%$ of the sample is 
merely young adults not married to a spouse, and about $85 \%$ of them not parenting any children. Thus, it can be assumed that they are individuals being fathered by either one or both parents and/or grandparents.

The mean values reported for the ethnonationalism scale highlighted that participants slightly and moderately agreed to the items in the scale, whereas the mean values reported for the family values scale highlighted that participants reported on both sides, moderately and slightly agree, and moderately and slightly disagree to the items on the scales.

Due to the fact that the sub-scales could not be combined to form a total scale score because both ethhnonationalism scale and family values scale had Cronbach's Alpha reliability statistics less than 0.70 and Inter-Item Correlations mean statistics less than 0.20 , reliability the reliability of each of the sub-scales had to be calculated.

Correlations to determine the relationship between the four sub-scales showed there was no correlation between ethnonationalism-theory and family values-hierarchy; there

\section{References}

1 Saucier G, Kenner J, lurino K, Malham PB, Chen Z, et al. (2014) Crosscultural differences in a global "survey of world views". J Cross-Cult Psychol 46: 53-70.

2 Triandis HC (2001) Individualism-collectivism and personality. J Pers 69: 907-924.

3 Triandis HC, Gelfand MJ (1998) Converging Measurement of Horizontal and Vertical Individualism and Collectivism. J Per Soc Psychol 74: 118-128.

4 Berry JW (1980) Introduction in methodology. In: Triandis HC, Lambart WW (eds.) Handbook of Cross-cultural Psychology. Basson: Allyn and Bacon 2: 1-29.

5 Madhavan S (2001) Female relationships and demographic outcomes in Sub-Saharan. Sociol Forum 16: 503-527.

6 Zimmer Z, Dayton J (2005) Older adults in Sub-Saharan Africa living with children and grandchildren. Pop Stud 59: 295-312.

7 Heckert J, Fabic MS (2013) Improving data concerning women's empowerment in Sub-Saharan Africa. Stud Fam Plann 44: 319-344. was a weak, positive correlation between ethnonationalismtheory and family-values-relationships; there was no correlation between ethnonationalism-multicultural civic nation and family values-hierarchy; and there was a weak, positive correlation between ethnonationalism-multicultural civic nation and family values-relationships.

Results for the comparisons between Tanzania, Ethiopia, and Kenya showed that for ethnonationalism-theory and family values-hierarchy the variances were equal between the three groups, alternatively for ethnonationalism-multicultural civic and family values-relationship the variances were not equal between the three groups.

Finally, the Scheffe Post-Hoc test (where variances were equal) showed significant differences between all three countries. Compared to the Dunnett T3 test (where variances are not equal) that showed significant differences between Tanzania and Kenya, and between Kenya and Ethiopia, no significant differences were found between Tanzania and Ethiopia.

8 Howard R (1982) Human rights and personal law: women in SubSaharan Africa. J Opin 12: 45-52.

9 Browne AW, Hazel R (1991) Female education in Sub-Saharan Africa: the key to development. Barrett Sour Comp Educ 27: 275-285.

10 Walter D, Omariba R, Boyle MH (2007) Family structure and child mortality in Sub-Saharan Africa: cross-national effects of polygyny. $J$ Mar Fam 69: 528-543.

11 Trotzer JP (1981) The centrality of values in families and family therapy. Int J Fam Ther 3: 42-55.

12 Sies MC (2014) Introduction: critical sustainability studies in SubSaharan Africa. Afr Today 61: vii-xviii.

13 Conner W (1994) Ethnonationalism: the quest for understanding. Princeton, New Jersey: Princeton University Press.

14 Langridge D (2007) Phenomenological psychology theory, research and method. England: Pearson Education Limited, p: 200.

15 Gravetter FJ, Forzano LAB (2012) Research methods for the behavioural sciences ( $4^{\text {th }}$ edn). Wadsworth: Cengage Learning.

16 Tarimo SJA (2008) The common good in Kenya and identities. Santana Clara University: Markkula Centre for Applied Ethics. 